\title{
Neuro-network technologies as a mean for creating individualization conditions for students learning
}

\author{
Dmitriy Bukreiev* \\ Bogdan Khmelnitsky Melitopol State Pedagogical University, Department of Computer Science and Cybernetics, Melitopol, Ukraine
}

\begin{abstract}
The study is devoted to the analysis of the current level of use of neural network tools to create conditions for individualization of student learning. The author presents the results of the analysis of scientific developments of scientists in the questions of the use of neural network approaches in the educational process, presents a range of basic modern directions of research and development, in particular: adaptive tests, individualization of learning, improvement of the level of distance education and others. The author emphasizes that modernity is characterized by an active increase in the number of students who choose for themselves individual and distance forms of education, which leads to the need for the development of modern technological systems of distance learning. For this purpose, the scientist conducts a comparative analysis of distance learning tools, their features and capabilities in terms of implementation of an automated intellectual system of individualization of the educational process.
\end{abstract}

\section{Problem statement}

Nowadays in the conditions of constant decrease of time for studying of students, in connection with the fast "aging" of knowledge and the great need of employers in the qualified personnel "today and now" the problem of intensification of education in the vector of creating opportunities of qualitative distance and individual form of learning with the possibility of assessment and adjusting the learning vector for each student, based on his or her personal skills and abilities. In connection with this, the world scientific and pedagogical space has been actively engaged in recent years in solving the problems of development of the means of accumulation and implementation of electronic means of processing large volumes of information. However, the current state of the art is insufficient, so there is a need to create means of processing, transmission and presentation of information, so it is advisable to create information systems for processing and issuing the necessary information, knowledge, information. Among these developments, issues related to intelligent information systems and means of classification and presentation of information in the educational space of the 21 st century.

\section{Analysis of recent research and publications}

When conducting research, inevitably work with information of a non-numerical and informal nature. As a result, there is a need to build a model and tools for quantitative description of processes and subjects related to pedagogy $[22,23]$. Of particular importance is the quality of education, which is understood as a cumulative indicator that reflects the result of the educational institution, as well as meeting the needs and expectations of society in the formation of different competencies of the individual.

Assessment of the quality of education depends on many factors, perhaps with unknown influence. Also in this case, there is a specificity of the "product" of education - a graduate of an educational institution, which should be considered as a complex system. According to research by V. V. Osadchyi and K. P. Osadcha the introduction of electronic education, services and tools for educators, students, leaders and parents in order to cooperate with all the above mentioned participants in the educational process, development of cloud technologies [25], which are leading in the scientific space, can be considered as a major among modern trends in informatization of education. However, before determining the quality received at the end of graduate studies, it is necessary to identify the factors that have the greatest impact on the student learning process. The following are traditionally distinguished among them [24].

1. Quality of interaction with the labor market in shaping the content of education: the level of involvement of employers in the formation of educational programs; the presence of a system of targeted training of specialists to order businesses; availability of agreements with foreign universities on joint implementation of educational programs; percentage of international students in relation to all students; level of development of the system of analysis and promotion of employment of graduates. And as noted in [27], employers' requirements for engineering and technical knowledge and skills are constantly being complicated. This is due to

Corresponding author: dessnight@gmail.com 
the accelerated evolution of technical skills, the emergence of new engineering professions and the penetration of technology in all areas of human life.

2. Quality of entrants and students: level of mastering of current educational material; comprehensive assessment of residual knowledge; the level of ability to solve applied problems; the level of final certification.

3. Quality of teaching technologies, educational and methodological and logistical support of the educational process: the level of the system of continuous control of student success during the semester and technology of student rating; the level of educational material; the level of methodological support of the educational process; the level of availability of specialized laboratories; level of organization of support of students' education according to individual plans.

4. Quality of the teaching staff: the level of conformity of the teacher's basic education with regard to the length of teaching and specialization; teacher's qualification level (academic degree, rank, position); level of socialpsychological relations of the teacher with students; introduction of the practice of inviting specialists from different industries to conduct training sessions.

Based on this, we can confidently say that about $50 \%$ of the total number of factors that affect students' level of knowledge and their quality as specialists in the future, focuses on the development of quality methodological materials and their adaptation to the individual qualities of students. In addition, as noted in the work of V. V. Osadchyi and I. V. Krasheninnik, the main deterrent to improving professional training in such conditions is a shorter, compared to the standard fouryear, bachelor's degree. During the two years of study it is not possible to provide the necessary time for a fullfledged practical training [26], but the creation of an individual trajectory of student's learning provides an opportunity to intensify the learning load and reduces the time for obtaining general competences. This confirms the need for a defined and detailed analysis of the current level of development of neural network technologies in the vector of their use as a means to create conditions for individualization of student learning.

During a detailed analysis of the scientific background, it was concluded that in the general sense the problem of development of neural network systems is devoted to a large amount of research literature, however, taking into account the specific topic of research limitations it is advisable to analyze only those studies in which the development systems are oriented to work in the educational space, particularly in the vector of adaptive learning. Questions of studying aspects of designing adaptive information learning environments were dealt with by V. Ya. Tsap [12], A. V. Narozhny [5]; from the point of view of the development of intellectual system of quality assessment of the educational process published their works A. A. Rybanov, V. P. Shevchuk, E. A. Prikhodko [9]; O. I. Petkovsky revealed the peculiarities of developing an intellectual system for assessing the level of development of general competences in students, which in turn confirms the view that the use of adaptive learning means qualitatively improves the process of information perception by students [8].

The works of P. I. Fedoruk focused on forecasting trends in the development of educational space in accordance with the needs of today and the development of adaptive testing tools, students, the scientist emphasizes the need to solve a number of problems of test control of knowledge in modern educational systems. In his work, the author notes that the methods and tools of classical test theory, despite the great potential of this technology do not solve many of the problems posed by the current level of educational development. He emphasizes that adaptive tests, in this case, allow to solve this problem and can be effectively used for solving any problems of optimization of educational process evaluation of efficiency of pedagogical innovations and technologies, monitoring, etc. [11]. Summarizing the results of the scientist, you can identify a number of positive features of the use of adaptive tests, so adaptive tests allow you to: adjust to the individual abilities of the student; to increase the accuracy of the assessment of the level of knowledge of each individual student by using a larger bank of questions of different levels of complexity; reduce the duration of the test and the number of questions required to achieve sufficient accuracy in assessing the student's level of knowledge; reduce student fatigue; ensure confidentiality by providing each student with an individual set of test tasks appropriate to his or her level of knowledge; simplify the procedure for making changes to the test bank. This study is key to us, as it confirms the assumption that the use of adaptive learning creates a powerful platform for creating personalized learning, which in turn significantly improves students' perception of information at every stage of learning.

Confirmation of our assumption is the work of A. S Dovbysh, who emphasized that further informatization of the educational environment is based on computerized work tools and neural network technologies and requires a fundamentally new information environment - a set of computer communication systems, databases and knowledge bases, as well as software complexes. The author note that knowledge control systems built on the basis of learning supportive decision-making systems have become widespread [4]. Such systems are a further development of expert systems. They provide a quantitative assessment of the performance of the system on the basis of selected criteria and models of alternative situations.

A number of works of Ukrainian scientists are devoted to the issues of information support of intellectual systems of vocational guidance and their use in the educational process. Research by V. V. Osadchyi reflects that the modern education system, using modern teaching methods, creates a serious alternative to traditional forms and methods of learning. With the discovery of computer intelligent systems by humanity, humanity is increasingly moving in the vector of transferring the learning process into an automated electronic process. However, studies show that a large number of human factors (such as defining a profession, choosing a life path, etc.) cannot be fully incorporated into an automated computer model. Scientist argue that the task is to at least partially support 
and provide the educational process with the means of intellectual information technology, reflecting the most important aspects of education and choice of profession [6]. The author emphasize that nowadays one of the main problems of education in general is the problem of effective professional orientation of young people in the conditions of dynamic labor market and educational services. We support the opinion of the authors and consider it appropriate to use intelligent Internet decision support systems for the choice of a profession to solve this problem. the user needs recommendations on how to proceed with the decision, because the choice of career path is a starting point stage of study of any discipline and leads to quality and informed learning.

From the point of view of the software of modern intellectual information systems, a number of works of scientists describes a neural network information exchange system for organizations that, using artificial intelligence concepts such as frames, production rules, and inheritance networks, aims to help people share and filter information transmitted through computer-based exchange systems using a rich set of templates. The works of H. Fujisaki, H. Kameda, S. Ohno, K. Abe, M. Iijima, M. Suzuki and others [2] are devoted to neural network systems for finding information that is the first stage of development of modern neural network system for educational needs. An interesting study, from the point of view of the above issues, is the study of B. FlorianGaviria, C. Glahn and R. Fabregat Gesa, regarding an experiment conducted with the support of 20 teachers. In the course of the experiment, teachers used a software suite for the effective use of the European Qualifications Framework during the students' study, the result of the experiment was the confirmation that the modern pedagogical process requires the development of software in order to improve quality of the educational process. According to the results of the experiment, the authors claim that certain software helps teachers to create contextual awareness, encourages students to deeper process of thinking and understanding, increases the efficiency of their perception of progress in the study of discipline and helps in creating a model of success or failure [1]. This research is very important in our scientific work because it confirms our view that the development of software education qualitatively improves the outcome of the entire learning process and provides an opportunity to influence the perceptions of students who are not involved or little involved in training.

\section{Analysis of the current state of the software}

In the framework of the study, it is advisable to analyze the current state of the currently existing software oriented to the pedagogical process. The analysis showed that in recent years, the use of "virtual classes" in which students are synchronized programmatically to create the psychological effects of competition and competition, has become very popular. In our opinion, one of the most important roles in the process of distance learning is the personification, which is carried out by regular periodic testing of the level of preparation, degree and speed of mastering the material by students.

During the analysis of the software, the dynamics with which new developments in the e-learning systems market are identified, indicate its rapid development. Each such system contains some special tools that are designed for the development of disciplines. Generally, they have the following advantages:

- significantly reduces the time to develop courses;

- reduce the overall costs of the organization to develop and maintain distance courses;

- modern level of functionality and communication capabilities of the graphical interface of distance courses is ensured;

- system bugs for beginning course developers are eliminated.

The use of specialized tools for the development of distance learning courses can significantly expand the audience of potential course developers, including teachers who do not have a thorough knowledge of information technology. Here is a description of the most popular distance learning systems.

BlackBoard offers solutions for Blackboard 9.1 educational institutions. The Blackboard 9.1 solution (Fig. 1) has three main applications:

- Blackboard Learning System;

- Black Blackboard Community Portal System (a unifying portal that provides access to resources, course administration, communications tools, charts, etc. for relevant categories of users);

- Black Blackboard Transaction System (an online system that provides student identification, access and management of tuition fees and more).

The Blackboard learning system consists of the following applications:

- Course management (a content management system that provides content management, communication tools, tests, surveys, exams; and providing various additional management tools for teachers);

- Blackboard Building Blocks architecture for interoperability and customization (a component that integrates various types of content and commercial applications with the Blackboard platform, as well as containing various utilities and applications for students and teachers);

- Advanced integration and system management (a system that integrates Blackboard solutions with various information systems).

Learning Space 5.5 (Lotus / IBM) software allows you to learn and teach in asynchronous mode (access to study materials at your convenience) and participate in online classes in real time. The user can create the content of the course in any program, and then place the created material in Learning Space 5.5 (Fig. 2).

The program has a flexible system of editing and administration of the course, allows you to choose different modes of study and keep track of the current results of students. Distance learning courses are organized as a series of lessons that can be self-contained, interactive or group-based. Self-study usually contains 
reading material and tests that you must complete after studying the material. Interactive lessons include attending virtual class lectures, engaging in online discussion or chatting, working with a virtual whiteboard, and a web-sharing system. Group classes include offline classes and online discussions, chats. All entries left during the course discussion are available throughout the course. The online classes are scheduled on a specific date and time and are conducted by the teacher in a virtual classroom in real time. Students' current scores (grade level, grade, time lost, number of hits, etc.) are stored in the database. This information is available to the teacher at any time in the form of various forms of reports.

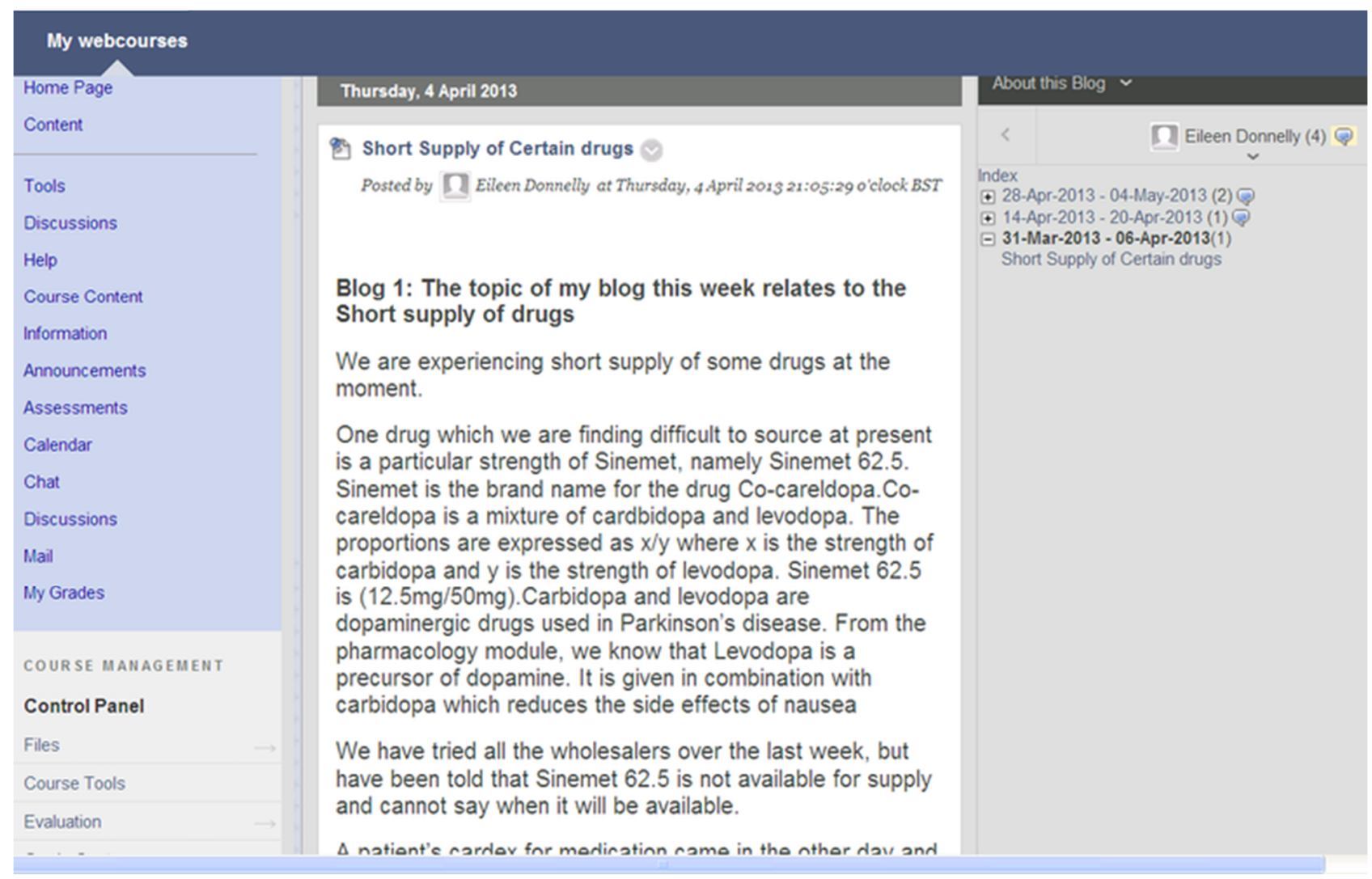

Fig. 1. View of the Blackboard Learning System.

$\leftarrow$ BACK TO COURSES
口 Course Discussions
三: Course Contents
自 Quiz - 22 (Error Detection 8)
自 Quiz - 21 (Spellings Check 2)
自 Quiz - 20 (Reading
Comprehension 5)
自 Quiz - 19 (Error Detection 7)
自 Quiz - 18 (Reading
Comprehension 4)
自 Quiz - 17 ( Error Detection 6)
自 Quiz - 16 (Sentence Fillers 3)
自 Quiz - 15 (Jumbled Sentences
2)

$\equiv$ English Language

Quiz - 22 (Error Detection 8)

\section{Error Detection 自 Question Paper}

Question 1

Single Correct Option $+1.00,-0.25$

During the Nehru years, Delhi has several small riots, (1)/ but given how resolutely the state (2)/ fought what it called the "communal poison", (3)/ the sparks did not become fires. (4)

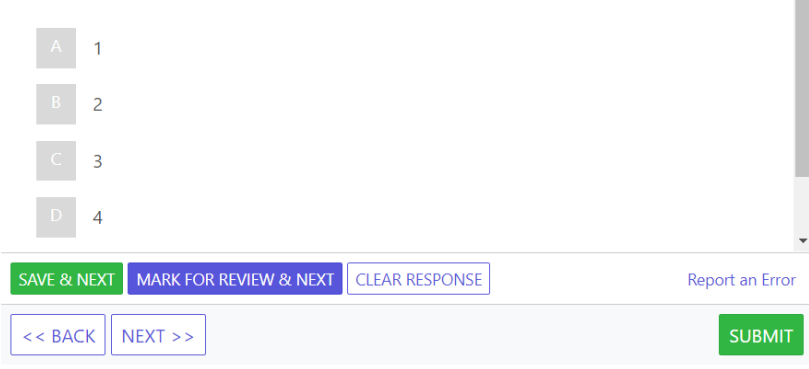

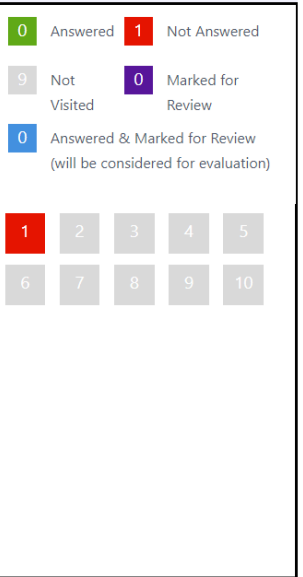

Fig. 2. View of Learning Space Learning System. 
Learning Space 5.5 has two main components: the Core module and the Collaboration module. The base module consists of a Core server (on which Learning Space 5.5 software is installed and running), a database server and a web server that creates the copyright. The Learning Space 5.5 server contains the core product software and is the core of the distance learning system. It provides an interface for entering and retrieving user and course information, storing and retrieving student results. It also supports a student interface designed to attend classes and view personal enrollment and learning outcomes. The database stores user data, course information, and listener ratings that are issued automatically or at the user's request. In addition to these database queries, Learning Space 5.5 contains several predefined report formats. The database contains course structure information and the course content is retrieved from the author's web server.

Moodle (Modular Object-Oriented Dynamic Learning Environment) is a suite of open source modular software
(GNU GPL) licensed to create distance learning courses and websites. This distance learning program is focused on teacher-student interaction and is also used to support full-time courses.

Moodle (Fig. 3) can be installed on any computer that supports PHP and works with MySQL, PostgreSQL, Microsoft SQL Server; the software is cross-platform [16]. The project is based on the principles of social constructivism:

- in today's learning environment, we are all potential teachers and students at the same time;

- we are successful learners, especially trying to create or explain something to people;

- observing the work of our colleagues is a major contribution to learning;

- understanding others makes it possible to study them more individually;

- the learning environment should be flexible, providing participants with an easy-to-use tool to meet their learning needs [22].

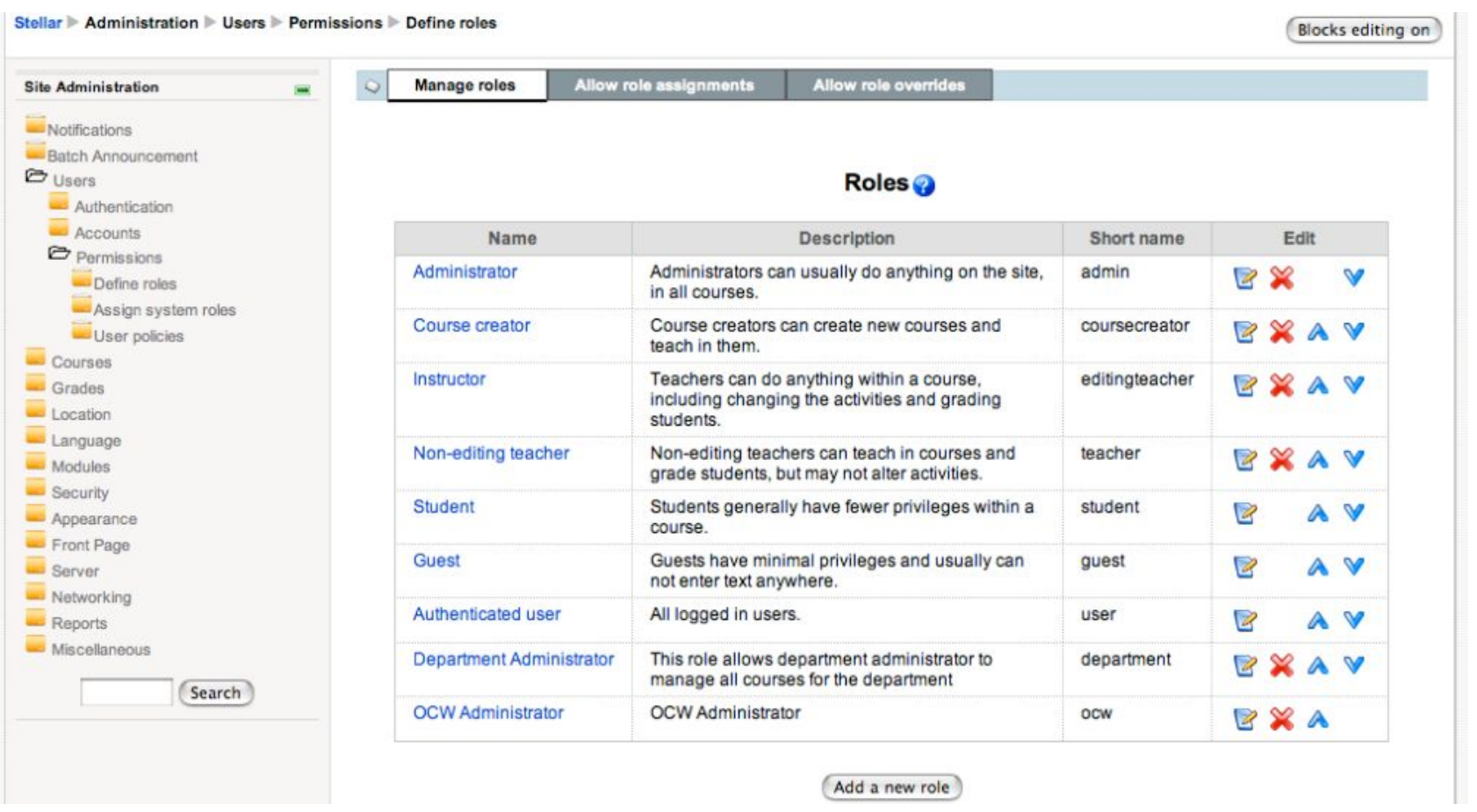

Fig. 3. View of the Moodle Learning System

SharePointLMS (Fig. 4) is a distance learning system developed on the powerful multi-functional MS Office SharePoint Server 2007. It is a comprehensive solution that integrates all users (teachers, students, administrators, etc.) into a single information and training space and provides tools cooperation. Unlike Moodle, Claroline and ATutor, the system is chargeable. It is used not only by educational institutions and training centers, but also by enterprises, organizations, and state structures [17].

However, having analyzed the existing software, we came to the conclusion that today we have many great examples of Web-based systems for distance learning, among them Blackboard, LearningSpace, Moodle and others. Such systems confidently use the benefits of information technology, but the study raises the need to determine the level of development of the aspect of the use of neural network technologies based on distance learning systems.

During further analysis, it can be concluded that elearning should not be developed in a vacuum; rather, it should be as close as possible to the needs and desires of students and adaptable as the course progresses. Assessing open source e-learning platforms in order to find the platform that is most suitable for adaptive expansion was thus very important. The extended platform could then be used in an online learning environment. Therefore, the overall functionality of the platform is as important as adaptability, and evaluation addresses both issues. 


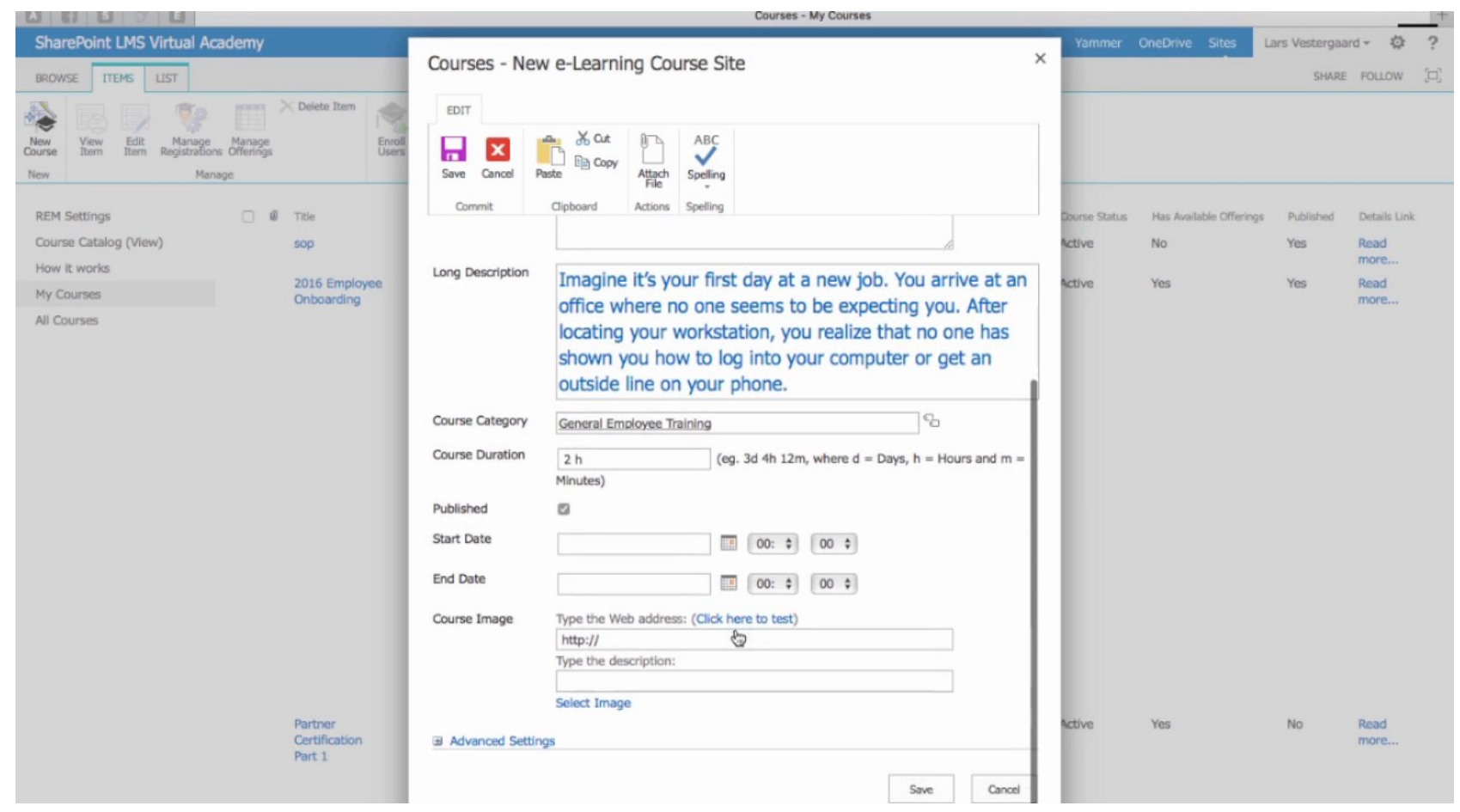

Fig. 4. View of SharePointLMS Learning System

After the preliminary assessment phase, nine open source e-learning platforms were analyzed in detail. The platforms were: Moodle, ATutor, Dokeos, dotLRN, ILIAS, LON-CAPA, OpenUSS, Sakai and Spaghettilearning. Based on the same survey, Moodle dominates the rating, achieving a top five times. The strengths of Moodle are the implementation of communication tools, their creation and administration of learning objects. An additional strength of Moodle is its comprehensive didactic concept as well as data tracking. In addition, the outstanding usability of Moodle maximizes the value in the usability category. For other platforms, ILIAS has received top honors in the technical, administration, and course management categories. Moodle achieved the best ratings. In addition, the second and third rank can be clearly assigned to ILIAS and Dokeos. According to pairwise comparisons, ATutor, LON-CAPA, Spaghettilearning and Open-USS ranked fourth, while Sakai and dotLRN came in last. The reason for the low Sakai rating is that only the main features are implemented so far. But the quality of these features is very good.

Moodle got the best overall performance as well as specific adaptation evaluation criteria.

After identifying the best platform for implementing adaptive learning, the level of technology development to create adaptive learning within individual and distance learning has been identified, and, with the technology revolution, lately, supporting adaptability in distance learning has become the interest of many researchers in the field, including technology. Agents can play a major role in empowering existing distance learning systems and providing adaptive experiences to meet students' needs. In the industry literature, agency technologies are also used in the context of e-learning systems to support adaptability and enhance the learning process. Agents are autonomous and can act reasonably in their environment. You can achieve a powerful system that is tailored to the needs of each student by using intellectual agents to develop e-learning systems.

Appropriate and up-to-date in the analysis, the EventState-Action (ESA) model was identified. This model is a jet model that responds in real time to any changes in its environment based on predefined rules and conditions. It is used in various critical systems, such as autopilot systems and antivirus systems. It takes form if the condition takes action. She can sense the environment and respond in a timely manner according to predefined rules and conditions. Most distance learning systems are designed with a database that stores and archives all the journals and student data and activities. Database triggers are based on predefined pedagogical rules that can be updated by teachers for any new requirements without restructuring the system. In the next section, we offer our framework to support adaptability across any distance learning systems that mirror hybrid architecture using agency technology. Thus, the system consists of three components: the ESA module, the multiagent module and the e-learning environment, as shown in Fig. 5, which qualitatively influences the process of individualization of the wind of learning and can be integrated with any system of distance learning.

This environment is an important part of adopting distance and blended learning. It also provides students and teachers with the tools and tools they need to improve the learning process. Moodle and Blackboard are some of the leading e-learning platforms. However, Moodle is probably the most popular and popular platform with over 53,346 sites reaching over 70 million users in 222 countries. 


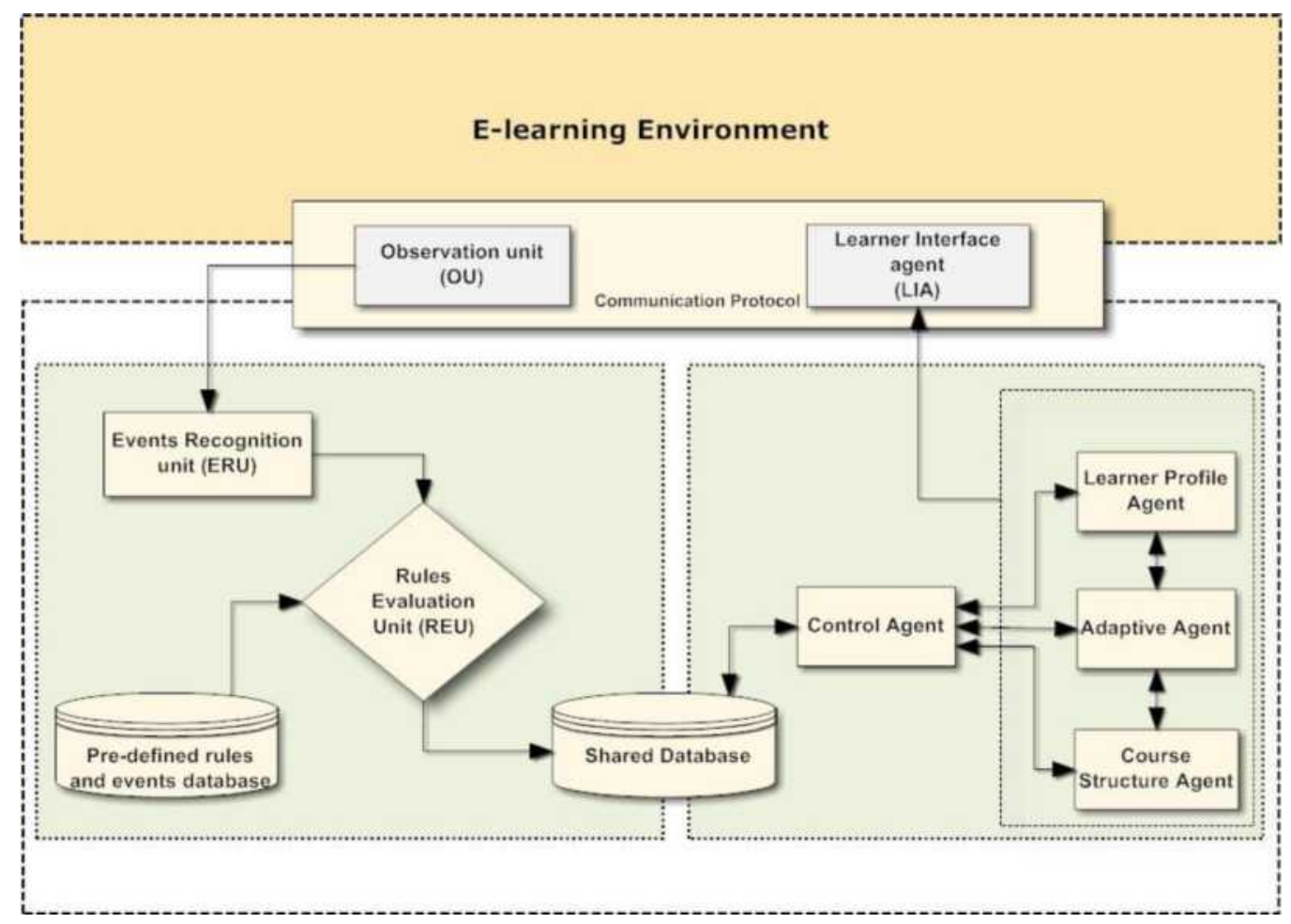

Fig. 5. Learning Automation System.

The ESA module is designed and used as a sensitive component. It is based on events that can occur in an elearning environment and respond accordingly. However, this process is a rule-based mechanism of database triggers such that events (training activities) such as registration and course access are monitored by an observation team linked to an electronic learning environment using a communication protocol. The event is then given to the Event Recognition Department to be recognized and classified before the evaluation process takes place. The Rule Evaluation Unit is responsible for determining whether or not the current event satisfies predefined pedagogical rules to provide the multi-agent module with the necessary and necessary data through a common database to provide adaptive student learning.

\section{Conclusions}

During a detailed analysis of scientific developments in the vector of this problem, it was concluded that in the general understanding of the problem of the development of neural network systems, a large amount of research literature is devoted, however, given the specific topic of limitation research, it is advisable to analyze only those studies in which the development of neural networks is oriented to work in the educational space. These studies have shown that high interest in scientists raises questions about the development of educational automation tools, including adaptive testing and individualization of the curriculum to improve the quality of perception of information by students, which confirms the assumption that the development of the neural network of student individualization, which improves the quality of education, is an urgent and urgent issue that needs to be addressed more quickly. For further development, existing software for creating conditions for distance and blended education was analyzed, but in the course of the study we concluded that none of the systems for introducing distance education met the criteria of fullfledged learning. Therefore, you need to combine highlevel programming languages with logical or knowledge languages, web technologies, and database management systems. In the following, we intend to apply and evaluate our approach in Moodle as a case study to provide adaptive content based on student learning styles using the Felder-Silverman learning style model (FSLSM).

\section{References}

1. B. Florian-Gaviria, C. Glahn, R. Fabregat Gesa, A Software Suite for Efficient Use of the European Qualifications Framework in Online and Blended Courses. IEEE Transactions on Learning Technologies 6(3), 283-296 (2013). doi:10.1109/TLT.2013.18

2. H. Fujisaki et al., Principles and design of an intelligent information retrieval system over the Internet with a multimodal dialogue interface. Paper presented at the Sixth European Conference on Speech Communication and Technology (EUROSPEECH, Budapest, 1999)

3. A.A. Andreev, Didactic Foundations of Distance Learning (Methods and means of distance learning). (Moscow, 2019).

4. A.S. Dovbysh, Fundamentals of designing intelligent systems (SSU Publishing House, Sumy, 2009)

5. A.V. Narozhny. Designing an Intelligent Programming Shell for Learning Based on the Specificity of the Credit Module System (2006) 
6. V.V. Osadchyi, Dissertation, Vinnytsia Mykhailo Kotsiubynskyi State Pedagogical University, 2005

7. E.G. Petrov, M.V. Novozhilova, I.V. Grebennik, Methods and means of decision-making in socioeconomic systems (2004)

8. O.I. Petkovsky, Development of a hybrid intellectual system with fuzzy neural network components for solving student's competence assessment problem (Altai State Technical University, Barnaul, 2012)

9. A.A. Rybanov, V.P. Shevchuk, E.A. Prikhodko, in Systematic problems of quality, mathematical modeling, information and electronic technologies, part 4, pp. 6-7 (2003)

10. V.F. Sytnik, Decision Support Systems (KNEU, Kiev, 2004)

11. P.I. Fedoruk. Adaptive tests: statistical methods for analyzing the results of knowledge test. Mathematical Machines and Systems 3, 122-138 (2007)

12. V.Y. Tsap, Designing automated learning environments as an intellectual system (Institute of Information Technologies and Learning Tools of the NAES of Ukraine, Kiev, 2011)

13. P.S. Yakushev, Analysis of Technologies and Systems for Controlling Electronic Learning: Report, Implementation of educational programs of innovative type in the field of IT (2007)

14. A.V. Yakushin, The Use of LMS in the Educational Process of the Teachers College, in Modern Information Technologies and IT Education, in Collection of Reports of the Scientific and Practical Conference, ed. by V.A. Sukhomlin, E.N. Nikelin, pp. 189-193 (2006)

15. eFront Teacher's Guide (2019)

16. A.V. Belozubov, D.G. Nikolaev, Moodle Distance Learning System: A Toolkit (St. Petersburg, 2007)

17. SharePointLMS Distance Learning System (Belitsoft, 2019)

18. ATutor User Documentation (2019)

19. ATutor Instructor Documentation (2019)

20. Claroline - Documentation (2019)

21. A.V. Andreev, S.V. Andreeva, I.B. Dotsenko, Elearning practice using Moodle (TTIUFU, Taganrog, 2008)

22. E.I. Selivanov, E.V. Panyushkina, The cornerstones of the qualimetry of competencies for compliance with the requirements of federal state educational standards of secondary vocational education. Fundamental and applied research in the modern world 3(5), 87-91 (2014)

23. E.V. Vorsina, T.A. Snigireva, Qualimetry of student's academic competence based on the analysis of educational texts. Bulletin of the N. A. Nekrasov Kostroma State University 18(3), 124-127 (2012)
24. I.G. Bartasevich, A system of criteria for the quality of students' education in higher education. Bulletin of the Astrakhan state tech. university, 217-220 (2008)

25. V. V. Osadchyi, K. P. Osadcha, Modern realities and trends of information and communication technologies development in education. Information Technologies and Learning Tools 48(4), 47-57 (2015). doi:10.33407/itlt.v58i2.1645

26. V. V. Osadchyi, I. V. Krasheninnik. Formation of short-cycle curricula content for future software engineers training on the basis of the labour market analysis. Information Technologies and Learning Tools $\quad \mathbf{5 8}(2), \quad 11-25 \quad$ (2017). doi:10.33407/itlt.v58i2.1637

27. V. V. Osadchyi, S. V. Symonenko. Foreign language as a means of communicative competence development of future software engineers. Information Technologies and Learning Tools 58(2), 38-48 (2017). doi:10.33407/itlt.v58i2.1645 